\title{
Research on Comprehensive Evaluation Index System of Software Outsourcing Personnel Training
}

\author{
Jingxian Wang \\ Department of College Foundation Education, Bohai University, Jinzhou, 121013, China \\ wjx_0610@126.com
}

Keywords: software outsourcing; personnel training; comprehensive evaluation; index system; index weight

\begin{abstract}
For the current status of the software outsourcing talent training and the lack of uniform evaluation criteria, this paper use AHP to research comprehensive evaluation index system of software outsourcing personnel training. First, from the foreign language knowledge, the overall quality, IT technology, software engineering, four areas, build a preliminary evaluation index system; Then study theoretical basis about how to use AHP to calculate the weight indicator system, including the construct matrix, single-level sort, level always sorts and so on; Finally, calculate the weight of each index in the initial evaluation index system, get the final evaluation system. The establishment of a scientific evaluation system is a basis for rational evaluation work, it is important for human resources management on software outsourcing and personnel evaluation research.
\end{abstract}

\section{Introduction}

In developed countries, the software industry is very powerful, Human resources are scarce, labor costs are higher, in order to reduce costs, take advantage of cheap labor in developing countries to manufacture software, delegated non-core businesses to external professional companies, this is the increasingly prosperous software outsourcing. The characteristics of the software outsourcing industry, non-polluting, low-power, high value-added and can provide large number of jobs, these are in line with our country's current industrial upgrading and transformation needs. Corresponds with the rapid development on software outsourcing is the lack of talent. Talents who come from universities and training institutions do not meet the requirements of outsourcing enterprises, talent training and talent needs disjointed, which requires a scientific and rational evaluation of talents comprehensive skills on software outsourcing, evaluation index system is a scientific evaluation of the basic work. By multiple perspectives analysis of talents on software outsourcing, reflect talents comprehensive ability on software outsourcing from the multiple levels, all-round, provide useful guidance for the enterprise human resources management and the improvement of talents comprehensive ability on software outsourcing.

\section{Establishment Of Preliminary Evaluation System}

In this paper, the indicators described here as a preliminary study to establish the evaluation index system [1]. The preliminary evaluation index system is divided into two, one level index including Foreign language knowledge, overall quality, IT technology, software engineering, four, each of a number of indicators under the two level indicators, as follows:

(1) Foreign language knowledge. Software outsourcing talents should not only understand the industry specific knowledge but also know software development skills. Meanwhile, software outsourcing talents must have good oral communication skills, especially understand and expression of software outsourcing technical jargon, to read and understand customer requirements made in foreign country and external design book. This requires in talent training process to enhance foreign country language education, use the advantage that China has, allow people to learn computer technology, with foreign country literacy and communication skills, and understanding of foreign country culture, lifestyle and working methods [2]. Two indicators on the evaluation of Foreign language knowledge, including: Basic level of Foreign country language, literature reading 
comprehension, writing skills, oral communication skills, Foreign country culture, customs, IT professional vocabulary, knowledge of the Foreign country software.

(2) Comprehensive Quality. It refers to people's level of knowledge, morality and various abilities of our comprehensive literacy. Along with new era, social is no longer just need the talent that masters a single high-tech skill, but the talent that has more comprehensive high-quality, wide knowledge, strong foundation, personal charm, to be able to cope with new challenges. The State Council issued "on the reform of education to promote quality education decision" request "make a establishment of evaluation and inspection system for quality education", without quality evaluation system, it is difficult to realize the talents quality education scientific [3]. Comprehensive high-quality talents have development potential, creativity and the ability to analyze and solve problems. According to China's software outsourcing feature, two indicators on the evaluation of comprehensive quality, include: unity and cooperation, spirit of dedication, ethical standards, technology innovation, communication skills, self-learning, adaption to new environment, English level.

(3) IT technology. The level of IT technology affects the development of China's software outsourcing; talent shortage has become a major constraints factor in the development of China's outsourcing. At present, China's software outsourcing projects are mainly low-end outsourcing exports, mainly focused on data entry, coding, testing, etc., the core technology R \& D is relatively low, less high-end projects, so that a high level of IT training technical talents have been become a very important task. To cultivate high-end IT technology professionals, first, establish a sound scientific curriculum, highlighting the importance of IT technology the role of the core courses; Second, increase the practice of practical training session, increase the synthesis, the ratio of the design of experiments, and strengthen practical ability; Third, use case-driven project to replace the traditional teaching mode, so that people really grasp the essence of IT technology; Fourth, promote the school-enterprise cooperation actively [4], put the knowledge Learned in the classroom into actual environment, master the IT technology as soon as possible. Two indicators on the evaluation of IT technology, including: development tools, programming skills, analysis and design, software testing, software knowledge, hardware knowledge, Internet knowledge, the operating system.

(4) Software Engineering. Develop and maintain software, using engineering concepts, principles, techniques and methods, put the time-tested and proven right management techniques and the best current techniques, methods and tools together, that is software engineering. Software engineering is a systematic method for software development, operation, maintenance, and retirement. To engage in software outsourcing permanently, we must follow the requirements of the contract quality and quantity time with the Foreign country side to provide software products. Accordance with the requirements of the contract quality and quantity provides software products on time to the Foreign country side According to the U.S. Survey of the implementation of software engineering, software development is still difficult to predict, only about $10 \%$ of the projects scheduled to cost and schedule delivery. Only about $10 \%$ of the project is delivered under the scheduled cost and progress. For this situation, it is necessary to use software engineering ideas and methods to guide software development, which requires the outsourcing talent in-depth study and understanding of the essence of software engineering and successfully applied to software outsourcing the actual work. Two indicators on the evaluation of software engineering capabilities, including: software engineering standard, outsourcing process specification, software project management, software development, writing documentation, quality control, configuration management. 


\section{Theoretical Basis Of Index Weight Calculation}

AHP is broken down into decision-making objectives, guidelines, programs and other levels, further qualitative and quantitative analysis of the decision-making methods. U.S. operations research expert, University of Pittsburgh professor T.L.Satty in the early 1970s, applies network theory and the multi-objective comprehensive evaluation method, proposes a hierarchical weight decision analysis method. AHP calculation process is shown in Fig. 1 [5].

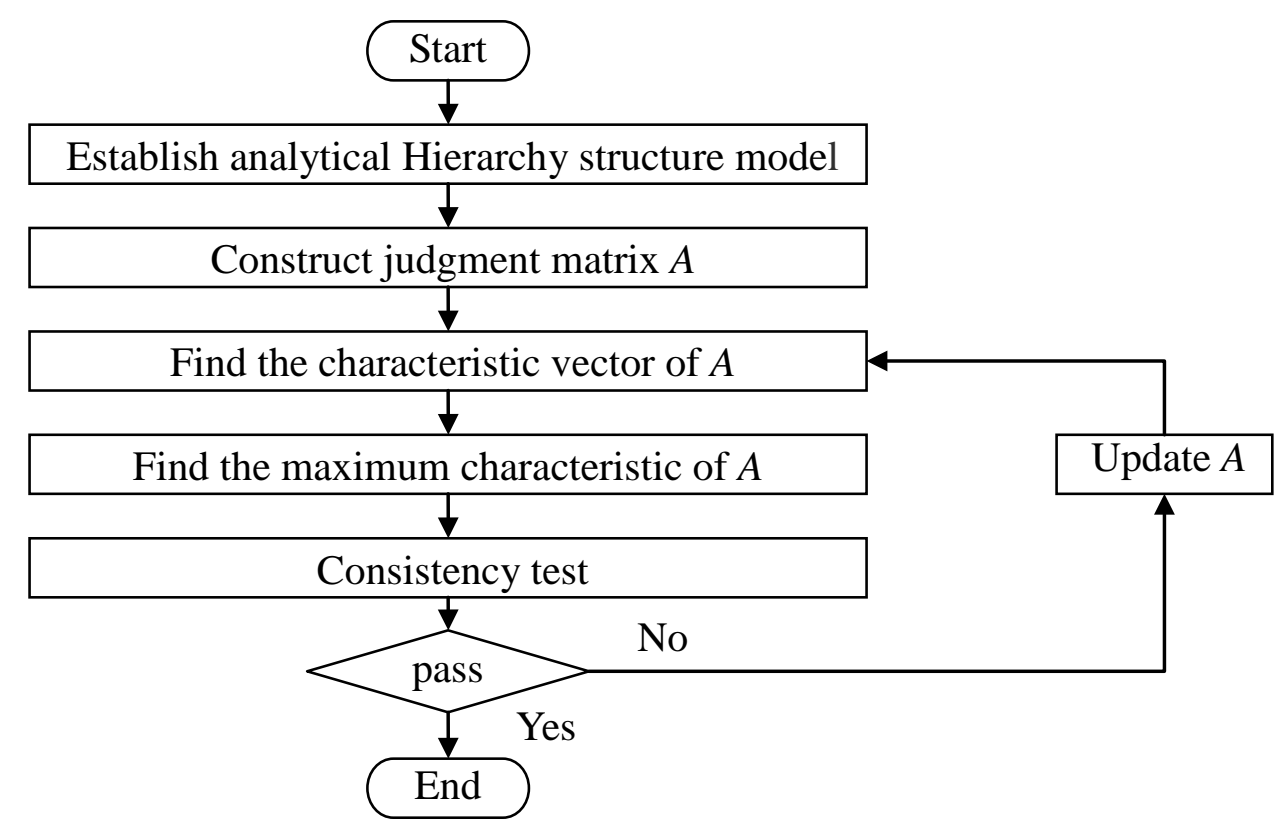

Fig. 1. AHP calculation process

(1) Construct Judgment Matrix. An important feature of AHP is to use the importance between the ratios of two forms expressed the importance of the corresponding two level programs. It is difficult to determine the relative importance of various indicators directly, therefore, the comparison between the two, according to their degree of importance rating, the results of pairwise comparison matrix is called judgment matrix [6].

(2) Level Single Sort. Level single sorting, is refers to use linear algebra knowledge of the biggest characteristic value to calculate matrix and the corresponding feature vector, normalize the feature vector, the results are weights from the evaluation index of the level about the relatively importance of the index above [7-8]. Usually have root method, and the plot method, here take root method.

Calculate the product of line index in judgment matrix. The formula is:

$$
M_{i}=\prod_{j=1}^{n} a_{i j}(i=1,2, \cdots, n)
$$

Calculate the product of the $n$-th root. The formula is:

$$
\overline{W_{i}}=\sqrt[n]{M_{i}}
$$

Normaliz the vectors $\bar{W}=\left\{\overline{W_{1}}, \overline{W_{2}}, \cdots, \overline{W_{n}}\right\}$. The formula is:

$$
w_{i}=\overline{W_{i}} /\left[\sum_{i=1}^{n} \overline{W_{i}}\right]
$$

(3) Level Always Sorts. It refers to the importance of weight of a level of all the indicators relative to the top (total goals). Calculate by a hierarchical structure from top to bottom along the layer by layer, calculate the relative importance of weights and the relative merits of ranking value about the indicators which is compared between top and the bottom. If want to kown the weight which is get using level always sorts is satisfied to accept, there is need for comprehensive conformance test. 


\section{Evaluation Index System}

(1) Results About Index Weight

Through research and expert scoring system to construct judgment matrix, use AHP to get Table 1 Evaluation index original weight of the table of comprehensive evaluation index system of software outsourcing personnel training, as the calculation process and the derivation of the length is too large, this only gives the final result.

Table 1. Original weight on comprehensive evaluation index system of software outsourcing personnel training

\begin{tabular}{|c|c|c|c|}
\hline \multicolumn{2}{|c|}{ one level index } & \multicolumn{2}{|l|}{ two level index } \\
\hline name & weight & name & weight \\
\hline \multirow{7}{*}{$\begin{array}{c}\text { Foreign } \\
\text { language } \\
\text { knowledge }\end{array}$} & \multirow{7}{*}{0.289} & Basic level of foreign language & 0.239 \\
\hline & & Literature reading comprehension & 0.198 \\
\hline & & Writing ability & 0.114 \\
\hline & & Oral communication skills & 0.167 \\
\hline & & Foreign country culture and customs & 0.083 \\
\hline & & IT professional vocabulary & 0.174 \\
\hline & & Knowledge of the foreign country software & 0.025 \\
\hline \multirow{8}{*}{$\begin{array}{l}\text { Comprehensive } \\
\text { quality }\end{array}$} & \multirow{8}{*}{0.213} & Unity and cooperation & 0.192 \\
\hline & & Spirit of dedication & 0.122 \\
\hline & & Ethical standards & 0.081 \\
\hline & & Technology Innovation & 0.117 \\
\hline & & Communication skills & 0.051 \\
\hline & & Self-learning & 0.226 \\
\hline & & Adapt to new environments & 0.174 \\
\hline & & English level & 0.037 \\
\hline \multirow{8}{*}{ IT technology } & \multirow{8}{*}{0.352} & Development tools & 0.115 \\
\hline & & Programming capability & 0.189 \\
\hline & & Analysis and design & 0.231 \\
\hline & & Software test & 0.166 \\
\hline & & Software Knowledge & 0.134 \\
\hline & & Hardware knowledge & 0.053 \\
\hline & & Network knowledge & 0.083 \\
\hline & & Operating system & 0.029 \\
\hline \multirow{7}{*}{$\begin{array}{l}\text { Software } \\
\text { engineering }\end{array}$} & \multirow{7}{*}{0.146} & Software engineering standards & 0.147 \\
\hline & & Outsourcing process specification & 0.251 \\
\hline & & Software project management & 0.218 \\
\hline & & Software development process & 0.042 \\
\hline & & Document writing & 0.172 \\
\hline & & Quality Control & 0.101 \\
\hline & & Configuration Management & 0.069 \\
\hline
\end{tabular}

(2) Evaluation Index System After Reduction

Two level indicators described above have different impact of comprehensive evaluation index system of software outsourcing personnel training, it can clearly express through Table 1 . But too many indicators, capacity assessment process is too cumbersome; Some of the indicators have little effect on the comprehensive ability, to simplify the capacity assessment, reduct out these indicators. The results are that each level indicator retains six secondary indicators after reduction, use the above method to recalculated the weight, get the comprehensive evaluation index system as shown in Table 2. 
Table 2. Weight on comprehensive evaluation index system of software outsourcing personnel training

\begin{tabular}{c|c|c|c}
\hline \multicolumn{2}{c|}{ one level index } & \multicolumn{2}{c}{ two level index } \\
\hline name & weight & name & weight \\
\hline \multirow{3}{*}{ Foreign } & & Basic level of foreign language & 0.246 \\
language & \multirow{2}{*}{0.289} & Literature reading comprehension & 0.204 \\
knowledge & & Writing ability & 0.117 \\
& & Oral communication skills & 0.170 \\
& & Foreign country culture and customs & 0.085 \\
& & IT professional vocabulary & 0.178 \\
\hline \multirow{3}{*}{ Comprehensive } & \multirow{2}{*}{0.213} & Unity and cooperation & 0.217 \\
quality & & Spirit of dedication & 0.136 \\
& & Ethical standards & 0.095 \\
& & Technology Innovation & 0.122 \\
& & Self-learning & 0.249 \\
& & Adapt to new environments & 0.181 \\
\hline \multirow{3}{*}{ IT technology } & \multirow{2}{*}{0.352} & Development tools & 0.125 \\
& & Programming capability & 0.204 \\
& & Analysis and design & 0.251 \\
& & Software test & 0.183 \\
& & Software Knowledge & 0.146 \\
Software & \multirow{2}{*}{0.146} & Network knowledge & 0.091 \\
\hline & & Software engineering standards & 0.151 \\
& & Outsourcing process specification & 0.264 \\
& & Software project management & 0.229 \\
& & Document writing & 0.180 \\
& & Quality Control & 0.105 \\
& & Configuration Management & 0.071 \\
\hline
\end{tabular}

\section{Conclusion}

Through the establishment of evaluation index system of software outsourcing personnel training, so that colleges and training institutions grasp the pulse of talent training, and then train more and more outstanding talents software outsourcing at all levels, promote our country's development on Foreign-oriented software outsourcing. This paper use AHP to construct evaluation index system, the accuracy of index weight depends on the value of matrix, the value of relative importance, sorting method and so on. This paper conducted a preliminary exploration on evaluation index system of talents comprehensive skills on Foreign-oriented software outsourcing, it is important for human resources management on Foreign-oriented software outsourcing and talent evaluation research.

\section{References}

[1] R. Q. Zhong, Y.J. Xie, L.M. Jiang, "Research and Practice on Talents Cultivation Mode of the Software and Information Service Outsourcing," Science and Technology Management Research, vol. 31, no. 6, pp. 189-193, 2011.

[2] Y. Ji, "A Brief Introduction to ITO in Japan," Journal of Qingdao Technical College, vol. 24, no. 1, pp. 68-72, 2011.

[3] Y. Lu, "Research on Comprehensive Quality Evaluation System of Outstanding College Students Based on Competency," Master’s degree of Suzhou University, 2007. 
[4] X.Z. Tian, "College IT professional talent training In the face of software outsourcing," China Education of Light Industry, vol. 13, no. 6, pp. 69-71, 2010.

[5] WU Qizong, "System Engineering," Beijing Institute of Technology Press, 2005.

[6] MBA Lib, "Analytic Hierarchy Process," http:/wiki.mbalib.com/wiki/, 2011-11-08.

[7] H. Jia, B. Zho, G.B. Liu, "Advantage Analysis of Risk Model Based on Analytic Hierarchy Process," Journal of Southwest Jiaotong University, vol. 30, no.2, pp. 72-76, 2009.

[8] Z.Y. Zhang, C.Q. Ye, K.F. Fan, et al., "Fuzzy analytic hierarchy process-based utilities evaluation and adoption for DRM security policies," Journal on Communications, vol. 30, no. S1, pp. 126-131, 2009. 